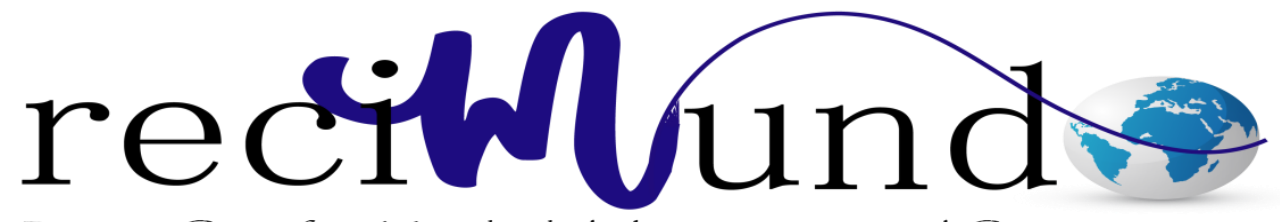

Revista Cientifica Mundo de la Investigación y el Conocimiento

Franklin Javier González Soriano ${ }^{\text {a }}$; Barbara de Lourdes Sambonino Garcia ${ }^{\text {b; }}$ Diógenes David Díaz Jiménez ${ }^{\mathrm{c}}$

La Dependencia en el Ecuador IESS

Revista Científica Mundo de la Investigación y el Conocimiento. Vol. 2 núm., especial, mayo, ISSN: 2588-073X, 2018, pp. 244-258

DOI: 10.26820/recimundo/2.esp.2018.244-258

Editorial Saberes del Conocimiento

Recibido: 09/12/2017

Aceptado: 14/02/2018

a. Universidad de Guayaquil-Docente; franklin.gonzalezs@ug.edu.ec

b. Universidad de Guayaquil-Docente; lourdes.samboninog@ug.edu.ec

c. Universidad de Guayaquil-Docente; diogenes.davidj@ug.edu.ec 


\section{La Dependencia en el Ecuador IESS}

Vol. 2, núm. Esp., (2018)

Franklin Javier González Soriano; Barbara de Lourdes Sambonino Garcia; Diógenes David Díaz

Jiménez

\section{RESUMEN}

La relación de dependencia en el Ecuador trata sobre las personas que necesitan de la ayuda de alguien más ya sea por edad, salud y/o discapacidad. Existen tres grados de dependencia, que se relacionan con los cuidados profesionales y no profesionales. En España la financiación cuenta por parte del Estado, mientras que en Ecuador se debe al pago de impuestos de los ciudadanos.

La Junta de Beneficencia del Ecuador es una de las entidades que ayuda a los adultos mayores en su debido cuidado, tratando de mejorar su calidad de vida, otro asilo conocido sería el Hogar San José que a diferencia del anterior mencionado éste es privado y requiere un pago de cada uno de los residentes del mismo o por parte de sus familiares. Cada una de estas entidades ha intentado brindar apoyo a los adultos mayores dándoles así la importancia que tienen dentro de la sociedad

Se presenta a continuación un análisis de los diferentes lugares de apoyo para con los adultos mayores existentes en Ecuador, comparándolo con el sistema de España y cuál sería su incidencia si fuese factible que se apliquen los mismos sistemas.

Palabras claves: Dependencia; SAAD; IESS; asilo. 


\title{
La Dependencia en el Ecuador IESS
}

Vol. 2, núm. Esp., (2018)

Franklin Javier González Soriano; Barbara de Lourdes Sambonino Garcia; Diógenes David Díaz Jiménez

\begin{abstract}
The relation of dependence in Ecuador is about people who need the help of someone else by age, health and / or disability. There are three degrees of dependency, which relate to professional and non-professional care. In Spain the financing counts on the part of the State, whereas in Ecuador it is due to the payment of taxes of the citizens.

The Ecuadoran Charity Board is one of the entities that helps elderly people in their proper care, trying to improve their quality of life, another well-known asylum would be the San José Home, which, unlike the previous mentioned one, is private and requires a Payment of each of the residents of the same or their relatives. Each of these entities has tried to provide support to the elderly, thus giving them the importance they have in society

An analysis of the different support sites for older adults in Ecuador is presented below, comparing it with the Spanish system and what its incidence would be if it were feasible to apply the same systems.
\end{abstract}

Key words: Dependence; SAAD; IESS; asylum. 


\section{La Dependencia en el Ecuador IESS}

Vol. 2, núm. Esp., (2018)

Franklin Javier González Soriano; Barbara de Lourdes Sambonino Garcia; Diógenes David Díaz

Jiménez

\section{Introducción.}

Una de las luchas constantes en el Ecuador ha sido combatir el abandono de los adultos mayores por parte de sus familiares. Por lo cual muchas de las entidades de cuidado para los ancianos buscan maneras de solventarse económicamente como pedir donaciones a los ciudadanos para ayudarlos, un ejemplo clave es la Junta de Beneficencia que está comprometida con la sociedad; de acuerdo con se puede tomar una pauta para comparar el tipo de sistema aplicado entre Ecuador y España como también identificar el resultado de la aplicación de la gratuidad en los centros de cuidado para los adultos mayores en Ecuador.

El Artículo 2 de la Ley 39/2006, de 14 de diciembre, de Promoción de la Autonomía Personal y Atención a las personas en situación de dependencia, define Dependencia como: "Estado de carácter permanente en que se encuentran las personas que, por razones derivadas de la edad, la enfermedad o la discapacidad, y ligadas a la falta o a la pérdida de autonomía física, mental, intelectual o sensorial, precisan de la atención de otra u otras personas o ayudas importantes para realizar actividades básicas de la vida diaria o, en el caso de las personas con discapacidad intelectual o enfermedad mental, de otros apoyos para su autonomía personal".

En el corazón de los ecuatorianos aún se puede observar la gentileza de los mismos, lo que une a los ciudadanos cuando de labor social se trata, en el país se han implementado organizaciones sin fines de lucro para ayudar a quienes más lo necesitan, y requieren atención prioritaria, como son los adultos mayores, con vocación de servicio, contribuyendo a las familias ecuatorianas.

La Junta de Beneficencia de Guayaquil está comprometida a mejorar la calidad de vida de las personas y proporcionarle bienestar en las áreas de salud, educación y atención al adulto mayor.

Revista Científica Mundo de la Investigación y el Conocimiento. 2 (Esp.). pp. 244- 


\section{La Dependencia en el Ecuador IESS}

Vol. 2, núm. Esp., (2018)

Franklin Javier González Soriano; Barbara de Lourdes Sambonino Garcia; Diógenes David Díaz Jiménez

Esta gran obra es posible gracias a la gestión llevada a cabo en cada una de sus instituciones. Es por esto que la Junta mantiene varios programas de ayuda que reflejan claramente los valores de generosidad y altruismo, la misión y los valores con los cuales fue concebida. Contamos con la infraestructura necesaria para llevar a cabo diferentes programas de ayuda social que benefician a los ecuatorianos en todos los aspectos de sus vidas.

Nuestro compromiso con toda la población guayaquileña, y ecuatoriana en general, abarca el cuidado de alrededor de 500 adultos mayores, brindándoles una atención digna y con amor en nuestros hospicios y asilos. Aquí acogemos a personas desamparadas y desposeídas, muchas veces abandonadas por sus familiares, y les brindamos todo el cariño y la calidez que necesitan para pasar esta última etapa de sus vidas en calma.

Son muchos los beneficiados de todos los servicios que la Junta de Beneficencia de Guayaquil brinda al adulto mayor. Los residentes son atendidos día a día de la mejor manera, y se procura brindarles no solo un servicio completo sino también el afecto del hogar ausente. Aparte de proveer alimentación y hospedaje, nuestras instituciones prestan servicio médico a cada persona que lo requiera, y además se realizan actividades de esparcimiento y terapias físicas, mejorando así su calidad de vida.

En España existe dependencia gratuita. La dependencia es un estado permanente en que se encuentran las personas, que por diversas razones (edad, enfermedad, discapacidad, etc.) necesitan la atención de otra u otras personas o ayuda para realizar las actividades básicas de la vida diaria.

Consejo de Europa define la dependencia como «la necesidad de ayuda o asistencia importante para las actividades de la vida cotidiana», o, de manera más precisa, como «un estado 


\section{La Dependencia en el Ecuador IESS}

Vol. 2, núm. Esp., (2018)

Franklin Javier González Soriano; Barbara de Lourdes Sambonino Garcia; Diógenes David Díaz Jiménez

en el que se encuentran las personas que por razones ligadas a la falta o la pérdida de autonomía física, psíquica o intelectual tienen necesidad de asistencia y/o ayudas importantes a fin de realizar los actos corrientes de la vida diaria y, de modo particular, los referentes al cuidado personal».

\section{Grados de dependencia}

Con el objetivo de agilizar los trámites para el reconocimiento del grado de dependencia, en el Consejo Territorial de julio de 2012 el Ministerio de Sanidad, Servicios Sociales e Igualdad y las comunidades autónomas acuerdan eliminar los niveles y mantener únicamente los tres grados:

\section{Grado III. Gran Dependencia.}

El grado III de gran dependencia es cuando la persona necesita ayuda para realizar varias Actividades Básicas de la Vida Diaria varias veces al día y, por su pérdida total de autonomía física, mental, intelectual o sensorial necesita el apoyo indispensable y continuo de otra persona o tiene necesidades de apoyo generalizado para su autonomía personal. Se corresponde a una puntuación final del Baremo de Valoración de la Dependencia de 75 a 100 puntos.

\section{Grado II. Dependencia Severa.}

El grado II de dependencia severa es cuando la persona necesita ayuda para realizar varias Actividades Básicas de la Vida Diaria dos o tres veces al día pero no requiere el apoyo permanente de un cuidador o tiene necesidades de apoyo extenso para su autonomía personal. 


\section{La Dependencia en el Ecuador IESS}

Vol. 2, núm. Esp., (2018)

Franklin Javier González Soriano; Barbara de Lourdes Sambonino Garcia; Diógenes David Díaz Jiménez

Se corresponde a una puntuación final del Baremo de Valoración de la Dependencia de 50 a 74 puntos.

\section{Grado I. Dependencia Moderada}

El grado I de dependencia moderada es cuando la persona necesita ayuda para realizar varias Actividades Básicas de la Vida Diaria al menos una vez al día o tiene necesidades de apoyo intermitente o limitado para su autonomía personal.

Se corresponde a una puntuación final del Baremo de Valoración de la Dependencia de 25 a 49 puntos.

Para conocer el grado de dependencia que tienes, debes solicitar en servicios sociales de tu localidad que un equipo de profesionales acuda a tu domicilio para valorar tu situación.

\section{Cuidados no profesionales}

Son los prestados a las personas dependientes en su domicilio, por personas de la familia o de su entorno.

\section{Cuidados profesionales}




\section{La Dependencia en el Ecuador IESS}

Vol. 2, núm. Esp., (2018)

Franklin Javier González Soriano; Barbara de Lourdes Sambonino Garcia; Diógenes David Díaz Jiménez

Son los prestados por una institución pública o entidad, con y sin ánimo de lucro, o profesional autónomo entre cuyas finalidades se encuentre la prestación de servicios a personas dependientes, ya sean en su hogar o en un centro.

\section{La financiación de la ley de dependencia}

La financiación de la Ley de Dependencia corre a cargo de la Administración General del Estado y las comunidades autónomas a partes iguales. Asimismo, la norma establece el copago de los beneficiarios, en función de su renta y patrimonio.

\section{Nivel mínimo}

El importe del nivel mínimo de protección es calculado y liquidado por el inmerso a las comunidades autónomas, mensualmente, en virtud del número de beneficiarios que figuran en el Sistema de información establecido.

\section{Prioridad de la prestación de servicios}

La intención del legislador con la ley era que se diera prioridad a la prestación de servicios (residencia, centro de día y de noche, tele asistencia, asistente personal, etc.) sobre las prestaciones económicas (dar una ayuda económica a la familia por los cuidados que dispensa al dependiente). Sin embargo, desde el comienzo de la aplicación de la ley la tendencia ha sido la contraria, se estaban dando alrededor de un 50\% de prestaciones económicas. Por ello, el Ministerio de Sanidad, Servicios Sociales e Igualdad estableció en 2013 nuevos criterios de asignación y reparto del nivel mínimo de protección, con el objetivo de estimular la prestación de servicios profesionales. 


\section{La Dependencia en el Ecuador IESS}

Vol. 2, núm. Esp., (2018)

Franklin Javier González Soriano; Barbara de Lourdes Sambonino Garcia; Diógenes David Díaz Jiménez

Todo ello queda reflejado en el Real Decreto de Nivel Mínimo, que prima los servicios frente a las prestaciones económicas por cuidados en el entorno familiar y obliga a las comunidades autónomas a la emisión de un certificado mensual que acredita que los datos introducidos en el Sistema de Información son reflejo de la realidad.

De esta manera, la financiación deja de ser lineal por beneficiario y grado. Ahora, las comunidades que den más prestaciones de servicios recibirán más financiación. Así, la distribución de los créditos de los Presupuestos Generales del Estado a trasferir a las comunidades autónomas para la financiación de la dependencia incorpora de forma progresiva durante cinco años (para evitar un cambio drástico en la financiación), una variable que pondera positivamente los servicios frente a la prestación económica por cuidados en el entorno familiar.

\section{El Sistema para la Autonomía y Atención a la Dependencia (SAAD)}

(Social, 2009) Es el conjunto de servicios y prestaciones económicas destinados a la promoción de la autonomía personal, la atención y protección a las personas en situación de dependencia, a través de servicios públicos y privados concertados debidamente acreditados, $\mathrm{y}$ contribuye a la mejora de las condiciones de vida de los ciudadanos.

Con la Ley 39/2006, de 14 de diciembre, se incorpora la atención a la dependencia al sistema público de protección social de nuestro país. Constituye un avance importante en el desarrollo de los derechos sociales en España. Tiene el carácter de legislación básica estatal.

A través de esta Ley, la dependencia ha entrado en nuestro sistema de protección social y ha modificado los actuales sistemas de servicios sociales. Contempla de forma específica la 


\section{La Dependencia en el Ecuador IESS}

Vol. 2, núm. Esp., (2018)

Franklin Javier González Soriano; Barbara de Lourdes Sambonino Garcia; Diógenes David Díaz Jiménez

prevención y la atención a las personas que se encuentran en situación de dependencia, y configura para ellas el derecho a un catálogo de servicios y prestaciones económicas. Como se dice en la Ley 39/2006 citada, en su exposición de motivos: "La necesidad de garantizar a los ciudadanos un marco estable de recursos y servicios para la atención a la dependencia y su progresiva importancia, lleva ahora al Estado a intervenir en este ámbito con la regulación contenida en esta Ley, que la configura como una nueva modalidad de protección social que amplía y complementa la acción protectora del Estado y del Sistema de la Seguridad Social”.

El Artículo. 1.1 de la Ley 39/2006 citada, establece que "La presente Ley tiene por objeto regular las condiciones básicas que garanticen la igualdad en el ejercicio del derecho subjetivo de ciudadanía a la promoción de la autonomía personal y atención a las personas en situación de dependencia, en los términos establecidos en las leyes, mediante la creación de un Sistema para la Autonomía y Atención a la Dependencia, con la colaboración y participación de todas las Administraciones Públicas y la garantía por la Administración General del Estado de un contenido mínimo común de derechos para todos los ciudadanos en cualquier parte del territorio del Estado español”. En Ecuador La afiliación al Instituto Ecuatoriano de Seguro Social (IESS) protege al afiliado en caso de eventualidades que afecten su capacidad de trabajo y la obtención de un ingreso. El seguro general obligatorio otorga cobertura para las siguientes contingencias: vejez, muerte, e invalidez (que incluye discapacidad); concede pensión por vejez, invalidez, viudez y orfandad, y asistencial no contributiva por vejez o invalidez. El subsidio transitorio por incapacidad es parte de esta protección.

\section{España}

Revista Científica Mundo de la Investigación y el Conocimiento. 2 (Esp.). pp. 244258 


\section{La Dependencia en el Ecuador IESS}

Vol. 2, núm. Esp., (2018)

Franklin Javier González Soriano; Barbara de Lourdes Sambonino Garcia; Diógenes David Díaz Jiménez

De acuerdo a (Carrión, 2005) lo que los ancianos más necesitan es que los escuchen, les hagan caso, que les cuenten lo que pasa en el mundo; hay que tener la voluntad de unirse a misiones humanitarias. En España la residencia de la tercera edad es pagada por el municipio, por lo general se les pone nombres que mejor suenen y transmitan tranquilidad.

Relata (Robledo, 2014) los ancianos en esta etapa de la vida se sienten como adolescentes que quieren explorar el mundo. El intercambio se gestó a través de Linkedage, una plataforma de comunicación y turismo enfocada a las casas de retiro, e Infoelder, la red de ayuda a la tercera edad y cuidado de mayores de España. "Fusionamos conceptos como Booking (buscador turístico) y Erasmus (programa de intercambio de estudiantes) adaptándolos a un segmento como el de la tercera edad que cada vez más irá en aumento.

Hay residencias que son como grandes hoteles con la diferencia de que ofrecen servicios de salud y saben cómo cuidar a las personas mayores. Lo que se les ofrece es una forma de viajar más segura", explica a BBC Mundo el esloveno Tomaz Lorenzetti, cofundador de la red junto a Marko Gucek. El deseo de viajar y seguir viviendo no termina, simplemente requiere de más planificación.

\section{Ecuador}

(Murgieri, 2015) Comenta que valor público se alcanza cuando se logra satisfacer lo más plenamente los objetivos de la institución, en nuestro caso, el cuidado socio-sanitario equitativo y de calidad de las personas mayores. 


\section{La Dependencia en el Ecuador IESS}

Vol. 2, núm. Esp., (2018)

Franklin Javier González Soriano; Barbara de Lourdes Sambonino Garcia; Diógenes David Díaz Jiménez

Existen varios desafíos que plantea el cuidado en Centros Residenciales, así podemos mencionar:

Desafío o controversia: es aquel derivado de la heterogeneidad y la diversidad en la tipología de los residentes: Doble concepción y exigencia de ser un lugar para vivir y un espacio de atención especializada con cuidados médicos y de enfermería. Una residencia no puede ser un efector de salud, pero es un aspecto que no debe ser descuidado. La provisión de medicamentos, las guías preventivas, la provisión de prótesis, las interconsultas a especialistas, la evaluación médica mensual son aspectos que no pueden ser dejados de lado.

Un desafío derivado del anterior es la problemática de convivencia. Cuando personas mayores tan diferentes unas de otras intentan convivir ocurre lo que podemos llamar colisión de estilos de vida y colisión de derechos.

Por otro lado, las personas que provienen de situación de calle muchas veces padecen patologías psiquiátricas larvadas sin diagnóstico ni tratamiento y frecuentes trastornos de personalidad, lo que también dificulta la convivencia. La frustración hace recurrente la queja.

Al hogar se lo ama y se lo odia. Es el lugar que les da pertenencia, protección y cuidado; si no estuvieran allí, vivirían en la calle, pero por otro lado no es lo que hubieran deseado de sus vidas. El ingreso a la institución es un factor de fragilidad como un cambio de domicilio, donde se desestructuran los mapas mentales y son desencadenantes a veces de síndromes geriátricos como las caídas. Muchos residentes temen la pérdida de control, a la vez que se alteran los hábitos, hay que cumplir horarios y reglamentos que si bien no son restrictivos tienden a ordenar la convivencia. 


\section{La Dependencia en el Ecuador IESS}

Vol. 2, núm. Esp., (2018)

Franklin Javier González Soriano; Barbara de Lourdes Sambonino Garcia; Diógenes David Díaz Jiménez

Cuando hablamos de centro abierto nos referimos a que los hogares deben ser de puertas abiertas y el ingreso con el consentimiento de la persona mayor. Muchas residencias privadas son de puertas cerradas y ello puede ser un concepto de privación ilegítima de la libertad. Un centro residencial también debe ser abierto para el ingreso de las personas de la comunidad (para prácticas pre-profesionales, acciones de voluntariado, espectáculos musicales de danza o teatro, etc.).

Mediante Decreto Supremo No 40 del 25 de julio de 1970 y publicado en el Registro Oficial N 15 del 10 de julio de 1970 se transformó la Caja Nacional del Seguro Social en el Instituto Ecuatoriano de Seguridad Social. El 20 de noviembre de 1981, por Decreto Legislativo se dictó la Ley de Extensión del Seguro Social Campesino. En 1986 se estableció el Seguro Obligatorio del Trabajador Agrícola, el Seguro Voluntario y el Fondo de Seguridad Social Marginal a favor de la población con ingresos inferiores al salario mínimo vital.

El Congreso Nacional, en 1987, integró el Consejo Superior en forma tripartita y paritaria, con representación del Ejecutivo, empleadores y asegurados; estableció la obligación de que consten en el Presupuesto General del Estado las partidas correspondientes al pago de las obligaciones del Estado.

En 1991, el Banco Interamericano de Desarrollo, en un informe especial sobre Seguridad Social, propuso la separación de los seguros de salud y de pensiones y el manejo privado de estos fondos. Los resultados de la Consulta Popular de 1995 negaron la participación del sector privado en el Seguro Social y de cualquier otra institución en la administración de sus recursos.

Revista Científica Mundo de la Investigación y el Conocimiento. 2 (Esp.). pp. 244258 


\section{La Dependencia en el Ecuador IESS}

Vol. 2, núm. Esp., (2018)

Franklin Javier González Soriano; Barbara de Lourdes Sambonino Garcia; Diógenes David Díaz Jiménez

La Asamblea Nacional, reunida en 1998 para reformar la Constitución Política de la República, consagró la permanencia del IESS como única institución autónoma, responsable de la aplicación del Seguro General Obligatorio.

El IESS, según lo determina la vigente Ley del Seguro Social Obligatorio, se mantiene como entidad autónoma, con personería jurídica, recursos propios y distintos de los del Fisco. El 30 de noviembre del 2001, en el Registro Oficial $N^{\circ} 465$ se publica la LEY DE SEGURIDAD SOCIAL, que contiene 308 artículos, 23 disposiciones transitorias, una disposición especial única, una disposición general. El Instituto Ecuatoriano de Seguridad Social se encuentra en una etapa de transformación, el plan estratégico que se está aplicando, sustentado en la Ley de Seguridad Social vigente, convertirá a esta institución en una aseguradora moderna, técnica, con personal capacitado que atenderá con eficiencia, oportunidad y amabilidad a toda persona que solicite los servicios y prestaciones que ofrece.

\section{Conclusiones.}

Según los estudios realizados se puede concluir que si implementamos el sistema gratuito de los asilos para adultos mayores como el que posee España, sería factible para los longevos, pero no sería rentable para la economía del país, puesto que atraviesa una situación económica difícil por endeudamiento con multinacionales como es China.

Se debe promover campañas de concientización hacia todos los ciudadanos para que realicen donaciones, labor social, y tomen mayor cuidado para con los adultos mayores, y así brindarles mayor cuidado y atención.

Revista Científica Mundo de la Investigación y el Conocimiento. 2 (Esp.). pp. 244258 


\section{La Dependencia en el Ecuador IESS}

Vol. 2, núm. Esp., (2018)

Franklin Javier González Soriano; Barbara de Lourdes Sambonino Garcia; Diógenes David Díaz Jiménez

\section{Bibliografía.}

Carrión, I. (2005). Un asilo de ancianos. El país.

Murgieri, M. (14 de Febrero de 2015). Asilo como última opción. El Telégrafo.

Robledo, J. (2014). Intercambio de asilos. Mundo.

Social, E. S. (2009). Las personas mayores en España. Madrid: Ediciones Grafo S.A. 